\title{
Equivalent Circuit Model of Cascade Connected Partial Core Resonant Transformers
}

\author{
Yanosh Irani, Dr. Andrew Lapthorn, Prof. Pat Bodger \\ Department of Electrical and Computer Engineering \\ University of Canterbury \\ New Zealand
}

\begin{abstract}
This paper presents a proof of concept and equivalent circuit analysis of a cascade arrangement of tunable $\mathrm{HV}$ testing transformers intended for field use. The transformers use a partial core with air completing the flux path and are tuned to resonate with insulation capacitance. This minimises the power drawn from the supply and the size and weight of the transformer. A prototype set of transformers were built to validate the model. Each transformer was modelled as a set of coupled inductors to determine the input impedance frequency response. Good agreement is shown between the modelled and measured input impedance. The inclusion of core loss resistance was shown to significantly increase the accuracy of the cascade model.
\end{abstract}

\section{INTRODUCTION}

Partial core resonant transformers(PCRTXs) were developed at the University of Canterbury to enable portable high voltage testing of generator stator insulation [1] [2]. They consist of two windings on a single rod of core steel. The extra limb and connecting yokes of a standard full core transformer are eliminated to save weight and the magnetic flux path is completed by the surrounding air. The inductance of the PCRTX is tuned to resonate with the insulation capacitance at power frequency. At resonance the insulation capacitance is fully compensated for by the transformer's own inductance. The only current drawn from the supply is to power the losses in the transformer and the insulation. The inductance of the PCRTX is tuned by inserting air gaps within the core or axially displacing the core.

The present test kit [3] was designed for testing generator stators but there is a need to extend its capabilities by generating higher voltages and energising larger loads such as XLPE cables. One method of doing this involves connecting smaller transformers in cascade as shown in Fig. 1 for two stages. The HV windings of each stage are connected in series. A tertiary coupling winding on the first stage with the same turns ratio as the primary is used to excite the primary of the second stage. The second stage is insulated from ground by placing the transformer on insulators or stacking it above stage 1 . The second stage transformer's internal insulation requirements are reduced resulting in smaller and more transportable transformers. The idea of cascading can be extended to $n$ stages with the first $n-1$ stages all being three winding transformers.

Cascaded transformers are ubiquitous in HV testing facilities worldwide [4] and resonant circuits are available commercially.

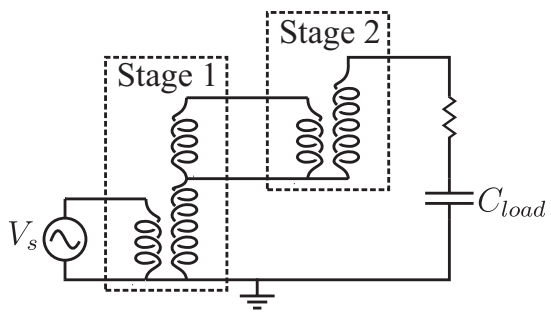

Fig. 1. Cascade transformer connection

They are usually full core liquid insulated machines and their size and weight limits their applications to fixed installations.

A cascaded set of PCRTXs is proposed where smaller units with less core steel and solid insulation are used to minimise size and weight. The supply power requirements will be reduced by the combined tuning each stage's inductance to resonate with the load capacitance. In order to design a set of PCRTXs optimised for cascaded performance, a new equivalent circuit model is required.

\section{MODEL}

Existing models of three winding transformers in cascade are based on the T-Equivalent circuit [5] [6] [7]. These models have accurately predicted the voltage ratio and distribution between stages of large HV testing transformers.

Two winding PCRTXs have been modelled as a pair of mutually coupled inductors as shown in Fig. 2 [8] .

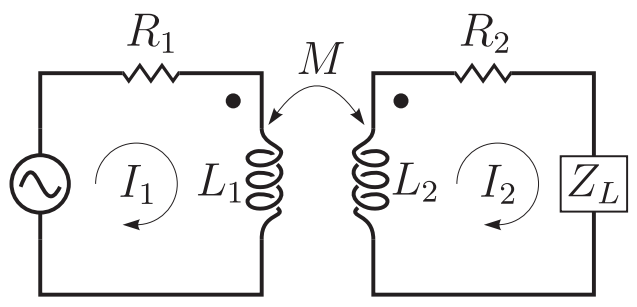

Fig. 2. Two winding PCRTX coupled inductor model

This model provided an accurate representation of the input impedance of a PCRTX. It was found in [9] that the addition of core losses to the two winding model gave no significant increase in accuracy.

By solving the mesh equations of the circuit, the input impedance is given by: 


$$
Z_{i n}=Z_{11}+\frac{\omega^{2} M^{2}}{Z_{22}}
$$

Where $Z_{11}=R_{1}+j \omega L_{1}$ and $Z_{22}=R_{2}+j \omega L_{2}+Z_{L}$.

This model can be extended to the three winding transformers used in the cascaded connection. However the complexity is increased as it is necessary to account for three mutual inductances and three self inductances. The matrix formulation of the winding terminal voltages is

$$
[V]=[L] \frac{d}{d t}[I]
$$

where $L$ is the inductance matrix

$$
[\mathbf{L}]=\left[\begin{array}{ccc}
L_{11} & M_{12} & M_{13} \\
M_{21} & L_{22} & M_{23} \\
M_{31} & M_{32} & L_{33}
\end{array}\right]
$$

The inductance matrix is symmetric due to the reciprocity theorem and is necessary for conservation of energy [10].

$$
M_{12}=M_{21}
$$

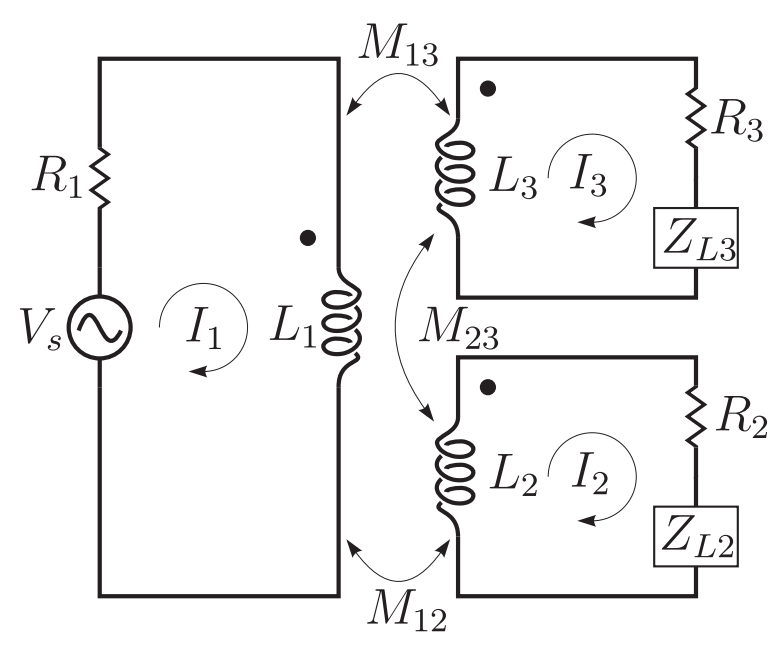

Fig. 3. Three winding PCRTX coupled inductor model

Consider a three winding coupled inductor with both secondary and tertiary windings loaded as shown in Fig. 3. Analysis of the mesh equations for this circuit yields the frequency domain matrix formula

$$
\left[\begin{array}{c}
V_{s} \\
0 \\
0
\end{array}\right]=\left[\begin{array}{ccc}
Z_{11} & -j \omega M_{12} & -j \omega M_{13} \\
-j \omega M_{21} & Z_{22} & -j \omega M_{23} \\
-j \omega M_{31} & -j \omega M_{32} & Z_{33}
\end{array}\right]\left[\begin{array}{c}
I_{1} \\
I_{2} \\
I_{3}
\end{array}\right]
$$

Where $Z_{j j}$ is the sum of the $j^{\text {th }}$ winding's losses $R_{j}$, the impedance due to self inductance $L_{j}$ and the load impedance $Z_{L j}$. Back substitution gives the input impedance of a three winding inductor with a loaded secondary and tertiary winding

$$
Z_{i n}=Z_{11}+\frac{\omega^{2}\left(M_{12}^{2} Z_{33}+M_{13}^{2} Z_{22}\right)+j 2 \omega^{3} M_{12} M_{13} M_{23}}{Z_{22} Z_{33}+\left(\omega M_{23}\right)^{2}}
$$

Extending the coupled inductor model to incorporate a cascaded stage involves adding the two winding inductor model across the tertiary winding as shown in Fig. 4. The core loss resistance $R_{c}$ is also added in parallel with the primary inductance of each transformer.

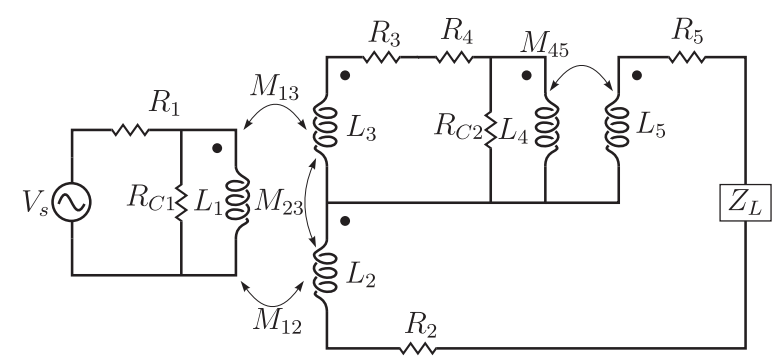

Fig. 4. Cascaded PCRTX coupled inductor model

Due to the complexity involved in finding an analytical solution, the circuit in Fig. 4 was solved using Simulink.

\section{PRototype DESIGN}

A prototype set of cascaded PCRTXs was built to validate the mathematical models [11] [12]. Two units were designed with rated secondary voltages of $20 \mathrm{kV}$ and primary voltages of $230 \mathrm{~V}$. The first stage was designed with a tertiary coupling winding also rated at $230 \mathrm{~V}$. An axisymmetric diagram of the first unit's winding arrangement is shown in Fig. 5.

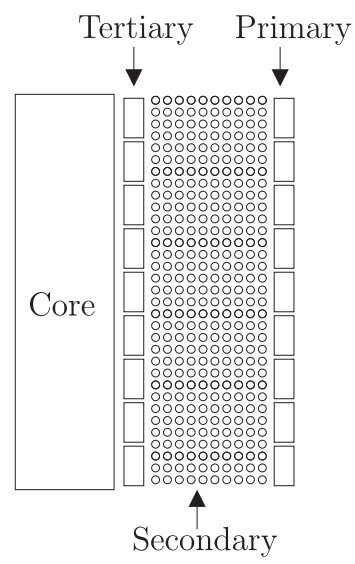

Fig. 5. Winding arrangement of three winding PCRTX

The tertiary coupling winding was wound first on the inner most layer using a $5 \times 2.5 \mathrm{~mm}$ rectangular aluminium conductor. One end of this winding was connected to the HV end of the secondary winding, wound using a $0.33 \mathrm{~mm}$ circular conductor. A primary winding was wound on the outside using the same conductor size as the tertiary.

The second unit was constructed in a similar fashion to the first except without the tertiary winding. Both units were solid 
insulated with a combination of Nomex NMN50 and a polymer resin, Sylgard. The finished cascaded PCRTX set is shown in Fig. 6.

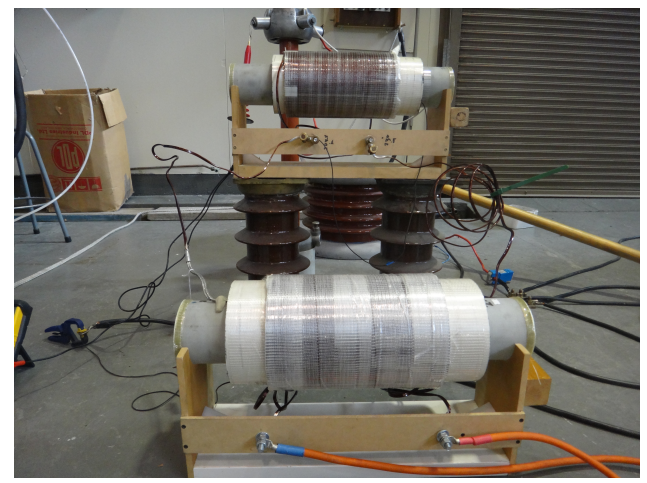

Fig. 6. Prototype cascade connected PCRTXs. The bottom unit is the first stage and the top unit is the 2 nd stage

\section{PARAMETER MEASUREMENTS}

The equivalent circuit parameters of the prototype two stage set of cascaded PCRTXs were measured using the resonant tuning test [9]. Using a variable frequency sine wave generator and a known capacitance $\mathrm{C}$, the secondary winding self inductances $L_{2}$ and $L_{5}$ can be found via

$$
L=\frac{1}{(\omega C)^{2}}
$$

The mutual inductances $M_{12}$ and $M_{23}$ were measured simultaneously with a known capacitor on the secondary winding.

$$
M=\frac{\sqrt{\left(\Re\left\{Z_{i n}\right\}-R_{p}\right) R_{s}}}{\omega}
$$

For the mutual impedance between the primary and tertiary winding, the series aiding method was used [13]. This relies on the fact that when the primary and tertiary windings are connected in series the total inductance measured is greater than the sum of the two self inductances.

$$
M_{13}=\frac{L_{t o t a l}-L_{1}-L_{2}}{2}
$$

The self inductances of the primary and tertiary windings $L_{1}, L_{3}$ and $L_{4}$ are in the order of $\mathrm{mH}$. Therefore the resonant tuning test was not performed on these windings due to the difficulty in sourcing large enough capacitors and a high voltage variable frequency supply. The self inductances of these windings were measured with an open circuit test.

$$
L=\frac{\sqrt{\left(\frac{V_{o c}}{I_{o c}}\right)^{2}-R_{p}^{2}}}{\omega}
$$

The core losses were determined by measuring the real power under open circuit conditions, $P_{o c}$. These losses are a combination of the winding losses $I^{2} R$ and the core losses $P_{C}$.
TABLE I. INDUCTANCE AND WINDING RESISTANCE MEASUREMENTS

\begin{tabular}{|c|c|c|c|}
\hline$L_{1}$ & $5.6 \mathrm{mH}$ & $R_{1}$ & $0.18 \Omega$ \\
\hline$L_{2}$ & $47 \mathrm{H}$ & $R_{2}$ & $803 \Omega$ \\
\hline$L_{3}$ & $6 \mathrm{mH}$ & $R_{3}$ & $0.15 \Omega$ \\
\hline$L_{4}$ & $5.7 \mathrm{mH}$ & $R_{4}$ & $0.2 \Omega$ \\
\hline$L_{5}$ & $45 \mathrm{mH}$ & $R_{5}$ & $741 \Omega$ \\
\hline$M_{12}$ & $414 \mathrm{mH}$ & $M_{13}$ & $5.21 \mathrm{mH}$ \\
\hline$M_{23}$ & $894 \mathrm{mH}$ & $M_{45}$ & $405 \mathrm{mH}$ \\
\hline
\end{tabular}

TABLE II. CORE LOSS RESISTANCE MEASUREMENTS

\begin{tabular}{|l|l|}
\hline$R_{C 1}$ & $65 \Omega$ \\
\hline$R_{C 2}$ & $61 \Omega$ \\
\hline
\end{tabular}

Conventional open circuit tests assume the winding losses can be ignored because they are insignificant compared to the core losses. In partial core transformers this assumption is false as the magnetising current is much larger. Therefore the winding resistance was measured with a microhmeter and the calculated copper losses were subtracted from the measured open circuit power.

$$
P_{C}=P_{o c}-I_{1}^{2} R
$$

The core loss resistance is calculated by ignoring the voltage drop across the leakage reactance and winding resistance as these were small in magnitude. The emf across the core is thus equivalent to the terminal voltage.

$$
R_{C}=\frac{V_{1}^{2}}{P_{C}}
$$

\section{RESULTS AND COMPARISON}

The cascaded set was tuned to a $100 \mathrm{nF}$ capacitive load and successfully energised to $25 \mathrm{kV}$ for a one minute test. It was calculated that the load capacitor was resonating with $92 \mathrm{H}$ of inductance, which is approximately the sum of both secondary winding self inductances.

The input impedance frequency response was measured using a CHROMA variable frequency sine wave generator. The cascaded set was used to drive a $100 \mathrm{nF}$ capacitive load. No tuning was performed and the cores were left in their central position. It can be seen in Fig. 7 that while the calculated and measured resonant frequency is matched, with the core losses excluded from the model the magnitude of the impedance peak at resonance is over estimated by approximately $50 \%$.

Re-running the simulation with the core loss resistance included gives the results shown in Fig. 8. There is much better agreement between the measured and calculated losses.

Additionally the model predicted that the current flowing in the primary winding of the first stage exceeded the current flowing in the primary winding of the second stage by a factor of 2.1. This matched the measured distribution of current. 

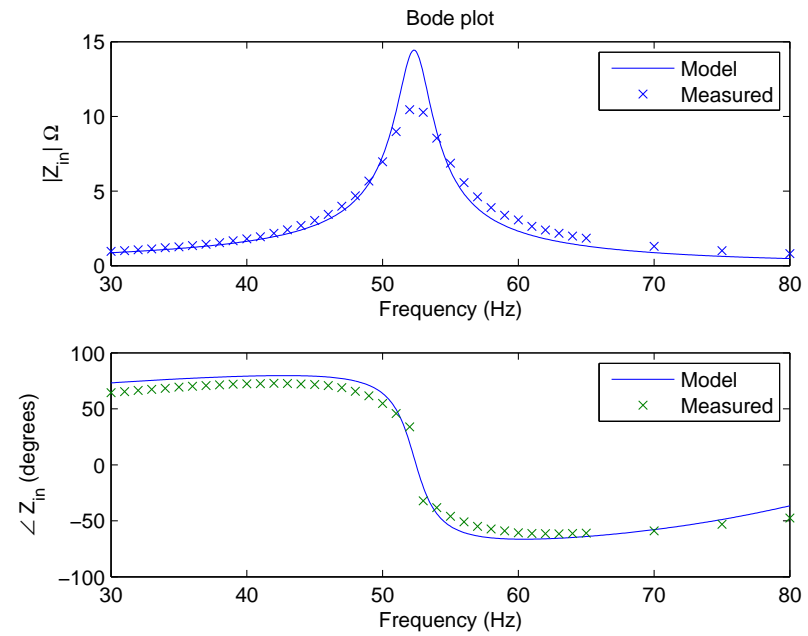

Fig. 7. Input impedance excluding core losses
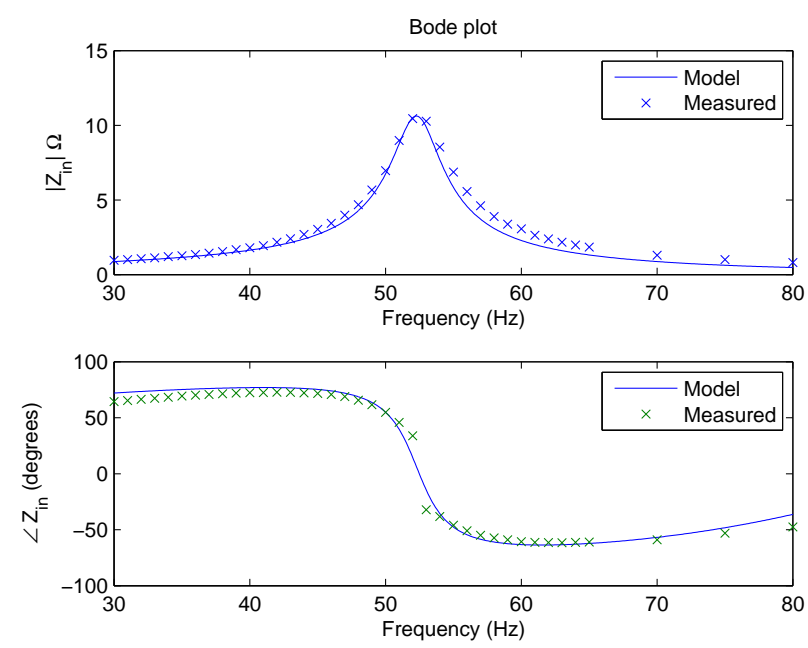

Fig. 8. Input impedance with core losses

\section{Discussion}

There is a small magnitude error at resonance caused by the exclusion of the core losses from the model of a single PCRTX. The cumulative effect of this error in the cascade connection presents a significant overestimation of input impedance. This would present greater inaccuracies when modelling three or more cascaded stages.

The benefits of the cascade connection are reduced insulation requirements and increased portability. The sacrifice is a reduction in resonant capacitance along with the increase in secondary winding inductance. Future designs of cascade PCRTXs will need to reduce the self inductance of each unit's secondary winding. This will allow the overall test kit to resonate with a greater load capacitance.

Reducing the series resistance of the windings and the parallel resistance of the core will be necessary to achieve a higher impedance at resonance. This could be accomplished by increasing the cross sectional area of the windings and using radially laminated cores.

\section{CONCLUSION}

A prototype set of two cascaded partial core resonant testing transformers was built and tested to prove the concept. Resonance at high voltage was achieved with the sum of each transformer's secondary winding inductance and a load capacitance of $100 \mathrm{nF}$. A new equivalent circuit model based on mutually couple inductors was used to predict the input impedance frequency response. Modelling the core loss resistance in a cascade connection was found to significantly increase the accuracy of the model.

\section{ACKNOWLEDGMENT}

The authors would like to thank Ken Smart, Dave Healy and Paul Agger for their technical support throughout this project.

\section{REFERENCES}

[1] P. Bodger and W. Enright, "A resonant transformer for high voltage testing of generator stators," Australian Journal of Electrical and Electronics Engineering, vol. 1, 2004.

[2] W. G. Enright, V. D. Bendre, S. C. Bell, and P. S. Bodger, "Field experiences using a prototype open core resonating transformers for a.c. high potential testing of hydro-generator stators," in TechCon Asia Pacific, Sydney, Australia, April 2008.

[3] S. Bell, "High voltage partial core resonant transformers," Ph.D. dissertation, University of Canterbury, Christchurch, New Zealand, 2009.

[4] E. Kuffel, W. Zaengl, and J. Kuffel, High Voltage Engineering Fundamentals, 2nd ed. Newnes, 2000.

[5] G. Olivier, G. Roy, R. Bouchard, and Y. Gervais, "Analytical model of hv cascade connected test transformers," in Electrical Machines and Converters - Modelling and SImulation - Proceedings of the IMACS International Symposium, H. Buyse and J. Robert, Eds. Elsevier Science Publishers B.V. (North-Holland), May 1984, pp. 185 - 191.

[6] G. Olivier, R. P. Bouchard, Y. Gervais, and D. Mukhedkar, "Frequency response of hv test transformers and the associated measurement problems," no. 1, pp. 141-146, 1980.

[7] B. N. Jayaram and D. J. Badkas, "Determination of output voltage in cascade-connected transformers," Part III Power Apparatus and Systems Transactions of the American Institute of Electrical Engineers, vol. 81, no. 3, pp. 936-938, 1962.

[8] S. C. Bell and P. S. Bodger, "Inductive reactance component model for high-voltage partial-core resonant transformers," IET Electric Power Applications, vol. 2, no. 5, pp. 288-297, 2008.

[9] S. Bell and P. Bodger, "Equivalent circuit for high-voltage partial-core resonant transformers," IET Electric Power Applications, vol. 2, no. 3, pp. 155-163, 2008.

[10] W. H. Hayt, J. E. Kemmerly, and S. M. Durbin, Engineering Circuit Analysis, 7th ed. McGraw-Hill, 2007.

[11] S. Velluppillai, "Partial core resonant testing transformer," University of Canterbury, Final Year Project, 2010.

[12] R. Meder, "Cascade partial core resonant transformer," University of Canterbury, Final Year Project, 2011.

[13] J. G. Hayes, N. ODonovan, M. G. Egan, and T. ODonnell, "Inductance characterization of high-leakage transformers," in Applied Power Electronics Conference and Exposition, 2003. APEC '03. Eighteenth Annual IEEE, vol. 2, 2003, pp. 1150-1156. [Online]. Available: http://ieeexplore.iee.org/stamp/stamp.jsp?arnumber=1179361 